PRIMER NOTE

\title{
Isolation and characterization of short tandem repeats in an invasive swimbladder nematode, parasitic in Atlantic freshwater eels, Anguillicola crassus
}

\author{
SÉBASTIEN WIELGOSS, MATTHIAS SANETRA, AXEL MEYER and THIERRY WIRTH* \\ Lehrstuhl für Zoologie und Evolutionsbiologie, Fachbereich Biologie, Universität Konstanz, 78457 Konstanz, Germany
}

\begin{abstract}
We describe the isolation and characterization of seven polymorphic short tandem repeats (STR) for the eel parasite Anguillicola crassus. This invasive swimbladder nematode endemic in East Asia was recently introduced into Europe. The number of alleles for each STR ranged from 13 to 39 per locus with observed heterozygosities between 0.49 and 0.98 . The Taiwanese population displayed higher genetic diversity compared to the Irish sample, an observation consistent with the Asian biogeographical origin of the nematode. Availability of the reported STR will facilitate the investigation of the population genetic structure with regard to multiple invasions.
\end{abstract}

Keywords: freshwater eel, invasive species, nematode, parasite, population genetics, STR

Translocation of organisms along with their parasites around the globe is of major relevance for the study of biological invasions and conservation genetics (Hochberg \& Gotelli 2005). The swimbladder nematode Anguillicola crassus (Dracunculoidea; Anguillicolidae) was recently introduced to North Atlantic eel populations from its natural host, the Japanese eel (Anguilla japonica). The nematode rapidly expanded into European and North African eel populations within three decades (Kirk 2003), which is explained best by commercial trade of infected eels from Asia to Europe (Koops \& Hartmann 1989). It is often the case that invasive parasites follow the main trading routes and switch from their natural reservoir to immunologically naïve hosts (Taraschewski 2006). The occurrence of the parasite in various thermohaline water regimes harbouring different intermediate and paratenic hosts ensures that eels in a broad range of habitats are constantly infected during their lifetime. The infection causes inflammatory reactions and fibrosis of the swimbladder wall, which may compromise the catadromous eels' spawning

Correspondence: Axel Meyer, Fax: +49 753188 3018;

E mail: axel.meyer@uni konstanz.de

*Present address: Ecole Pratique des Hautes Etudes, Département Systématique et Evolution (Cc39), Muséum National d'Histoire Naturelle, 16 Rue Buffon, 75005 Paris, France migration in the open ocean (Kirk 2003). Thus, the nematode is thought to be a serious threat to the already sharply declining freshwater eel stocks in Europe (Wirth \& Bernatchez 2003).

In order to determine the nematode's population structure and demography, and to examine the possibility of multiple independent invasions, we isolated and characterized highly variable short tandem repeats (STR). Extracting total genomic DNA (gDNA) free from host tissues is a crucial step. The nematode's intestine is filled with eel blood, which must be carefully removed to separate the tissues of the parasite from the host's. Forty eels from Lake Constance, Germany, were dissected and their swimbladders screened for adult nematodes. Twelve adult stages were found alive, and female ovaries and uteri and the seminal ducts of males were dissected under a binocular microscope to rule out internal and external contaminations with eel tissue. Total gDNA was extracted following standard protocols of Proteinase K digestion (Sambrook et al. 1989). If required, hard-to-digest tissues (oviducts) were subsequently disintegrated by heating at $65^{\circ} \mathrm{C}$ for $30 \mathrm{~min}$ in a Tris/EDTA-buffered cetyltrimethylammonium bromide (CTAB) solution at a final concentration of $1 \% \mathrm{~m} / \mathrm{v}$. Resuspended DNA was checked for contamination using both eel-specific mitochondrial (for the cytochrome $b$ gene) and genomic DNA primer pairs (Wirth \& Bernatchez 2001). 
Short tandem repeats were isolated and identified from partial genomic libraries enriched for CA or CT repeats with the help of a magnetic bead technique following the protocol of Tenzer et al. (1999), including modifications by Garner et al. (2000). Enriched DNA was ligated into the pCRII-TOPO cloning vector and transformed into chemically competent Escherichia coli TOP10 cells supplied with the TOPO TA Cloning kit (Invitrogen), following the manufacturer's recommendations. After plating, the cells grew overnight on $1 \times \mathrm{LB}$ agar, containing $50 \mu \mathrm{g} / \mathrm{mL}$ of ampicillin and $80 \mu \mathrm{g} / \mathrm{mL}$ of X-gal. Single colonies were picked and regrown for $14 \mathrm{~h}$ in a 96-well-plate-format in $150 \mu \mathrm{L}$ liquid $1 \times$ LB medium, containing $50 \mu \mathrm{g} / \mathrm{mL}$ of ampicillin. Bacterial cells were disrupted using a 5-min heat shock at $94{ }^{\circ} \mathrm{C}$ and lysates were directly taken as polymerase chain reaction (PCR) templates. Inserts were identified and screened for STR using M13 forward and reverse primers. Sequencing reactions were performed with Perkin Elmer's recommended protocol for BigDye version 3.1 sequencing chemistry on a 3100 Genetic Analyser (ABI-Hitachi).

Screening of 265 inserts of $91 \mathrm{CA}$ and 174 CT clones revealed nine unique STR, of which seven could be successfully amplified later on (Table 1 ). These markers are the basis for inferring genetic structure within newly invaded eel populations and tracking down the source populations of the parasite. Specific primer pairs were designed using the PRIMER 3 software (Rozen \& Skaletsky 2000). The same PCR protocol was carried out on a GeneAmp PCR System 9700 (Perkin Elmer-ABI) for all loci as follows: a $15 \mu \mathrm{L}$ total reaction contained $1 \times$ of Genaxxon's Reaction Buffer S (10 mm Tris- $\mathrm{HCl}, \mathrm{pH} 8.3,50 \mathrm{~mm} \mathrm{KCl}$, $1.5 \mathrm{~mm} \mathrm{MgCl} 2,0.1 \%$ Triton X-100); $200 \mathrm{~nm}$ of each dNTP; $1 \mathrm{U}$ of RedTaq (Genaxxon); $200 \mathrm{~nm}$ of each primer and 10 $100 \mathrm{ng}$ of gDNA. An initial 5 -min hot start at $94{ }^{\circ} \mathrm{C}$ was followed by the 35 cycles of denaturation for $35 \mathrm{~s}$ at $94^{\circ} \mathrm{C}$, annealing for $35 \mathrm{~s}$ at $55^{\circ} \mathrm{C}$ and elongation for $45 \mathrm{~s}$ at $72^{\circ} \mathrm{C}$, finished by a post-elongation step of $10 \mathrm{~min}$ at $72^{\circ} \mathrm{C}$. Forward primers with an attached fluorescent label at the $5^{\prime}$-end allowed multiplexing of differently coloured amplicons. Alleles were run against the internal size standard GENESCAN-500 ROX (ABI), analysed using GENESCAN and scored in GENOTYPER (ABI software version 3.7 NT).

Single loci were tested for Hardy Weinberg equilibrium (HWE) and pairs of loci for linkage disequilibrium (LD) in one European and one native Taiwanese population of A. crassus each, using GENEPOP version 3.4 (Raymond \& Rousset 1995) with 10000 dememorization steps, 1000 batches and 1000 iterations. Sequential Bonferroni tests (Dunn-Sidák method) were conducted to correct for errors in multiple comparisons among means (Sokal \& Rohlf 1995). None of the loci showed significant linkage disequilibrium after Bonferroni correction, and all loci but one, AcrCT53, agreed with Hardy Weinberg expectations. A subsequent analysis run in MICROCHECKER (van Oosterhout et al. 2004) indicated the presence of null alleles for the deviating locus. The Taiwanese population displayed higher genetic diversity compared to the Irish sample, for similar sample sizes (Table 1), an observation consistent

Table 1 Short tandem repeats of the nematode species Anguillicola crassus based on two populations, rivers Shannon (Ireland) and Kao Ping (Taiwan)

\begin{tabular}{|c|c|c|c|c|c|c|c|c|c|c|c|}
\hline \multirow[b]{2}{*}{ Locus } & \multirow{2}{*}{$\begin{array}{l}\text { Primer sequences }\left(\begin{array}{ll}5^{\prime} & 3^{\prime}\end{array}\right) \\
\text { (including label descriptors) }\end{array}$} & \multirow{2}{*}{$\begin{array}{l}T_{\mathrm{am}} \\
\left({ }^{\circ} \mathrm{C}\right)\end{array}$} & \multirow{2}{*}{$\begin{array}{l}\text { GenBank } \\
\text { Accession no. }\end{array}$} & \multirow[b]{2}{*}{ Core motif } & \multirow[b]{2}{*}{$A$} & \multirow{2}{*}{$\begin{array}{l}\text { Size range } \\
\text { (bp) }\end{array}$} & \multirow{2}{*}{$\begin{array}{l}\text { Null } \\
\text { genotypes } \\
(\%)\end{array}$} & \multicolumn{2}{|c|}{$\begin{array}{l}\text { Shannon } \\
(n=37)\end{array}$} & \multicolumn{2}{|c|}{$\begin{array}{l}\text { Kao Ping } \\
(n=44)\end{array}$} \\
\hline & & & & & & & & $H_{\mathrm{E}}$ & $H_{\mathrm{O}}$ & $H_{\mathrm{E}}$ & $H_{\mathrm{O}}$ \\
\hline AcrCT04 & F CAGGGACATGGAAAGGTGT & 58 & EF216845 & $(\mathrm{CT})_{56}$ & 39 & 100260 & 0 & 0.91 & 0.95 & 0.95 & 0.98 \\
\hline AcrCT27 & $\begin{array}{l}\text { H TCCGATACCCGCATTATACAC } \\
\text { TCCTTGGCCAATTGATTTAAC }\end{array}$ & $\begin{array}{l}01 \\
60 \\
59\end{array}$ & EF216846 & $(\mathrm{CT})_{49}$ & 29 & 72200 & 0 & 0.91 & 0.89 & 0.93 & 0.84 \\
\hline AcrCT29 & $\begin{array}{l}\text { H CAAATGGCAATTTCGACCAG } \\
\text { TGCGTTCGTTCAGTATAGCA }\end{array}$ & $\begin{array}{l}61 \\
58\end{array}$ & EF216847 & $(\mathrm{CT})_{36}$ & 15 & 168228 & 0 & 0.77 & 0.62 & 0.83 & 0.69 \\
\hline AcrCT53 & $\begin{array}{l}\text { F TCGTCCTTTTCCATTTGTCC } \\
\text { GCGGAACAAAACAAATAAATG }\end{array}$ & $\begin{array}{l}60 \\
57\end{array}$ & EF216848 & $(\mathrm{CT})_{59}$ & 37 & 73230 & 2.5 & 0.91 & $0.49^{*}$ & 0.95 & $0.76^{*}$ \\
\hline AcrCT54 & $\begin{array}{l}\text { N AAACCCCATACTGTTCCTTGC } \\
\text { TCGAGAAGGCAAATATCTAGGC }\end{array}$ & $\begin{array}{l}60 \\
60\end{array}$ & EF216849 & $(\mathrm{CT})_{14} \mathrm{CC}(\mathrm{CT})_{6}$ & 18 & 168236 & 1.25 & 0.80 & 0.78 & 0.82 & 0.87 \\
\hline AcrCT103 & $\begin{array}{l}\text { N CTGCCGATCCAACAAGACG } \\
\text { GTTTCCCCTGAAAAAGTTCG }\end{array}$ & $\begin{array}{l}63 \\
59\end{array}$ & EF216850 & $(\mathrm{CT})_{41}$ & 24 & 92160 & 0 & 0.87 & 0.81 & 0.93 & 0.91 \\
\hline AcrCA102 & $\begin{array}{l}\text { H AAGTCTAACCCCGCTATTTTTG } \\
\text { GCGCATGTTTCTGTGTGTATAAG }\end{array}$ & $\begin{array}{l}59 \\
60\end{array}$ & EF216851 & $(\mathrm{CA})_{6} \mathrm{TACATA}(\mathrm{CA})_{5}$ & 13 & 297332 & 0 & 0.59 & 0.54 & 0.86 & 0.86 \\
\hline
\end{tabular}

*Deviation from Hardy Weinberg equilibrium $P<0.0001$ (Bonferroni corrected $\alpha=0.00174$ ).

$\mathrm{F}, 6 \mathrm{FAM}, \mathrm{H}$, HEX, N , NED; $n$, sample size; $A$, number of alleles; $T_{\mathrm{am}}$, melting temperature; $H_{\mathrm{E}^{\prime}}$ expected heterozygosity,

$H_{\mathrm{O}^{\prime}}$ observed heterozygosity. 
with the Asian biogeographical origin of the nematode. Due to the fact that other species of the genus Anguillicola are difficult to obtain, we were only able to test one specimen of the closely related species, Anguillicola globiceps (Moravec \& Taraschewski 1988) for cross-species amplification. We found that for all but two primer pairs, AcrCT53 and AcrCA102, amplicons could be obtained.

\section{Acknowledgements}

This work was supported by grants of the Deutsche Forschungs gemeinschaft (DFG) to T.W. and the University of Konstanz to A.M. We acknowledge Sonja Erath and Ursula Topel for technical assistance. Kieran McCarthy and Horst Taraschewski kindly supplied nematode and eel fin clip samples. Dave Gerrard gave valuable comments on the final version.

\section{References}

Garner TW, Gautschi B, Rothlisberger S, Reyer HU (2000) A set of CA repeat microsatellite markers derived from the pool frog, Rana lessonae. Molecular Ecology, 9, 21732175.

Hochberg ME, Gotelli NJ (2005) An invasions special issue. Trends in Ecology \& Evolution, 20, 211.

Kirk R (2003) The impact of Anguillicola crassus on European eels. Fisheries Management and Ecology, 10, 385394.

Koops H, Hartmann F (1989) Anguillicola infestations in Germany and in German eel imports. Journal of Applied Ichthyology, 1, 4145.
Moravec F, Taraschewski H (1988) Revision of the genus Anguillicola Yamaguti, 1935 (Nematoda: Anguillicolidae) of the swimbladder of eels, including descriptions of two new species, A. novaezelandiae sp.n. and A. papernai sp. n. Folia Parasitologica, 35, 125146.

van Oosterhout C, Hutchinson WF, Wills DPM, Shipley P (2004) micro checker: software for identifying and correcting genotyping errors in microsatellite data. Molecular Ecology Notes, 4, 535538 .

Raymond M, Rousset F (1995) genepop (version 1.2): population genetics software for exact tests and ecumenicism. Journal of Heredity, 86, 248249.

Rozen S, Skaletsky H (2000) PRIMER 3 on the WWW for general users and for biologist programmers. Methods in Molecular Biology, 132, 365386.

Sambrook J, Fritsch E, Maniatis T (1989) Molecular Cloning: A Laboratory Manual. Cold Spring Harbor Laboratory Press, Cold Spring Harbor, New York.

Sokal RR, Rohlf FJ (1995) Biometry. W.H. Freeman, New York.

Taraschewski H (2006) Hosts and parasites as aliens. Journal of Helminthology, 80, 99128.

Tenzer I, Ivanissevich SD, Morgante M, Gessler C (1999) Identification of microsatellite markers and their application to population genetics of Venturia inaequalis. Phytopathology, 89, 748753.

Wirth T, Bernatchez L (2001) Genetic evidence against panmixia in the European eel. Nature, 409, 10371040.

Wirth T, Bernatchez L (2003) Decline of North Atlantic eels: a fatal synergy? Proceedings of the Royal Society of London. Series B, Biological Sciences, 270, 681688. 